\title{
Analyzing the Experiences of Female Leaders in Civil Service in Kazakhstan: Trapped between Economic Pressure to Earn and Traditional Family Role Expectations
}

\author{
Aliya Kuzhabekova, Saltanat Janenova \& Ainur Almukhambetova
}

To cite this article: Aliya Kuzhabekova, Saltanat Janenova \& Ainur Almukhambetova (2018) Analyzing the Experiences of Female Leaders in Civil Service in Kazakhstan: Trapped between Economic Pressure to Earn and Traditional Family Role Expectations, International Journal of Public Administration, 41:15, 1290-1301, DOI: 10.1080/01900692.2017.1387142

To link to this article: https://doi.org/10.1080/01900692.2017.1387142

\section{进 Published online: 26 Oct 2017.}

Submit your article to this journal $\sqsubset$

Џll Article views: 215

View Crossmark data ¿ð 


\title{
Analyzing the Experiences of Female Leaders in Civil Service in Kazakhstan: Trapped between Economic Pressure to Earn and Traditional Family Role Expectations
}

\author{
Aliya Kuzhabekova ${ }^{a}$, Saltanat Janenova ${ }^{b}$, and Ainur Almukhambetova ${ }^{c}$

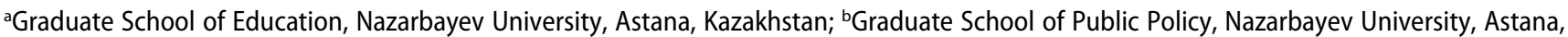 \\ Kazakhstan; 'Graduate School of Education, Nazarbayev University, Astana, Kazakhstan
}

\begin{abstract}
This paper analyzes the experiences of female leaders in civil service in a rapidly changing political, socio-cultural, and economic context of Kazakhstan. The research presents an analysis of the views of female managers on advantages and disadvantages of having women-leaders in civil service; on challenges and opportunities they are facing; on strategies they use to advance to and succeed in leadership positions. The important finding of this research is that female leaders in Kazakhstan are challenged with a clash of western, neo-liberal values and traditional expectations of women in the society. The analysis is based on primary data with women holding managerial positions in civil service.
\end{abstract}

\section{KEYWORDS}

female; leader; gender; civil service; Kazakhstan
One of the achievements of the Soviet state was large-scale expansion of female participation in different aspects of economic and political life (Kandiyoti, 2007). Female emancipation argument was incorporated to the Soviet ideology to justify female participation in labor; while public child-care provision and female-friendly social policy were organized to release females from the traditional role of a primary care-taker (Pascall and Manning, 2000). Despite the notable achievements, female representation in leadership, including representation among top civil service administrators remained unimpressive (Katz, 2001).

In post-Soviet Kazakhstan, two decades of economic reforms were accompanied with changes in cultural values and practices. The dissolution of ideological control has allowed for simultaneous penetration of liberal Western attitudes to family and female participation and for the resurgence of traditional practices, which emphasized the importance of family values and the dominant role of a male as its head. In combination, these economic and ideological influences should have affected the opportunities for female participation in civil service and governance, as well as their ability to advance to the positions of leadership. However, the extent to which this happened is not particularly clear.
To our knowledge, no studies were conducted so far that would explore the experiences of females in leadership positions in civil service in Kazakhstan. Meanwhile, such a study would be valuable, since it would shed light on the extent to which such access is problematic and the causal mechanism and repair strategies, which could be used to adjust gender policies aimed at increasing female participation. It could potentially contribute to gender-related policies, female promotion practices, and research on gender issues in the post-Soviet and larger international contexts.

\section{Gender policy and gender-representation statistics in modern Kazakhstan}

Since the early days of independence, Kazakhstan has committed to achieving gender equality. In 1998, Kazakhstan joined the Convention on the Elimination of All Forms of Discrimination Against Women. Kazakhstan has also ratified the Convention on the Political Rights of Women and the Convention on the Nationality of Married Women. In addition, international treaties on civil, political, economic, social, and cultural rights have been signed.

In November 2003, the government approved the Concept of Gender Policy. Several strategic priorities of the concept are related to female representation in

CONTACT Aliya Kuzhabekova Aliya.Kuzhabekova@nu.edu.kz 853 Kabanbay Batyr Avenue, Astana, Kazakhstan, 010000, Graduate School of Education, Nazarbayev University.

(c) 2017 Taylor \& Francis Group, LLC 
leadership, including the achievement of balanced participation of men and women in the power structures, the provision of equal opportunities for women's economic independence, entrepreneurship and career development, and creation of conditions for equal exercise of rights and responsibilities in a family. A number of commissions, furthermore, have recently been established, including the National Commission for Women and the Family and the Association of Business Women of Kazakhstan, demonstrating the emergence of concerted efforts to address the issue of female participation in leadership.

There have been important advances in women's participation in public life in Kazakhstan, yet women remain underrepresented in key decision-making posts. As of 2014, the share of women in the parliament was $26.2 \%$, which was slightly below the OECD average (28.6\%) (IPU, 2014). In 2015, women occupied only 3 of the 17 ministerial positions (Nurlybek, 2015). Female politicians tend to be involved in social sectors (healthcare, education, social protection) and to have less political experience than males.

Importantly some policy initiatives are directed at the promotion of females to leadership positions in civil service. One of the key performance indicators set by the strategic plans is achievement of $30 \%$ representation of women in decision-making positions by 2017 . However, Gender Equality Strategy for 2006-2016 contains insufficient measures to increase women's political representation. Most of the actions proposed are declarative in nature and are not supported by practical steps. As an example, the issue of quotas for the next 10 years is expected only to be further investigated, while most of the legislative documents rarely undergo gender-sensitivity appraisal in practice despite the mandatory legal requirement for the government bodies to conduct such an appraisal.

\section{Literature review}

While limited in number, there are existing studies of the experiences of women in civil service, including experiences of career advancement in various countries. In this section, we summarize the main themes in the available literature.

\section{Global trends in female representation in governance}

Women in civil service are concentrated at lower levels and their representation at senior leadership positions is low in majority of countries (Guy \& Newman, 2004; Naff, 2001). As Stivers (2002) points out, the US government, though attempting to promote women's interests, historically excluded women from leadership and authority. Research in this area tested different contexts and fields, for instance, American state agencies (Bowling, Kelleher, Jones, \& Wright, 2006; Brudney, Hebert, \& Wright, 2000), US state legislatures (Cammisa \& Reingold, 2004), US public relations sector (Wrigley, 2002), US senior executive service (Sabharwal, 2015), Australian public sector (Connel, 2006), etc. The existing research tells us that female underrepresentation in leadership is a reality for the majority of countries across the globe (Bowling et al., 2006; Kim, 2004; Naff, 2001).

\section{Rationale for women participation in governance}

Many arguments have been advanced to provide a rationale for the importance of female representation in governance. Dahlerup (1978) provided a summary of the existing arguments, claiming that women have: (1) the right to governance representation reflecting their population representation; (2) unique experiences, biologically or socially constructed, that males fail to represent; (3) conflicting interests with men, which cannot be represented by men; (4) an important function as role models for other women; (5) insufficient critical mass in governance participation necessary to promote their interests; (6) an impact on democratization of governance if gender parity is achieved (Dahlerup, 1978).

\section{Barriers to women's advancement to governance}

While women participation in governance is widely accepted as important, women continue to face barriers in advancement and "leak through" the career pipeline of the public service. Metaphorically described as the impenetrable "glass ceiling" and "sticky floor," many invisible, but strong barriers impede women from advancing along the career ladder in civil service at lower (floor) and higher (ceiling) levels (Naff, 1994, 2001; Sabharwal, 2015; Yap \& Konrad, 2009). There is a limited body of research on challenges of the women who have managed to break "the glass ceiling": female leaders tend to be judged less favorably than their male counterparts, receive less support from the peers and subordinates, receive more criticism, and face different types of subtle discrimination (Ryan \& Haslam, 2005).

A variety of obstacles facing women in career advancement can be subdivided in the following main types: (1) sociocultural obstacles; (2) balancing familywork responsibilities; (3) male-oriented organizational 
culture of civil service; (4) stereotypic association of women with some traditional occupations.

\section{Sociocultural obstacles to women's advancement in civil service}

Among sociocultural obstacles to females' representation in public service are existing social, cultural, and religious norms that hold the male over the female (Adusah-Karikari \& Ohenmeng, 2014; Bawa \& Sanyare, 2013; Cammisa \& Reingold, 2004; Connel, 2006; Eagly \& Carli, 2007; Ryan \& Haslam, 2005; Zafarullah, 2000). In less economically developed countries girls have less access to basic education than boys, are less likely to move to higher levels of education and, consequently, cannot compete for managerial positions later in life (Adusah-Karikari \& Ohenmeng, 2014; Bawa \& Sanyare, 2013; Zafarullah, 2000). Such societies still "look with disdain" at the women, who try to pursue a career in male-dominated areas (Bawa \& Sanyare, 2013, p. 288) or may prohibit female participation in such areas by law (Zafarullah, 2000).

In more economically advanced countries there are no formal prohibitions and discrimination, but there are still barriers associated with sociocultural norms (McBride \& Parry, 2016; Rudman, Moss-Racusin, Phelan, \& Nauts, 2012). Even in developed countries women are expected to play the primary role in child rearing and housekeeping, while males are hold responsible as breadwinners as a result of the division of labor between the sexes. From early years, women are socialized to be submissive and subservient to males. Many females lack the ambition to become leaders, are rejected promotions in favor of males due to stereotypes about their excessive emotionality, irrationality, and lower intellectual and leadership potential as compared with males, as well as expectations about their ability to balance work and family responsibilities.

\section{Family-work balance}

The existing literature suggests that difficulty in balancing family responsibilities and work is one of the greatest challenges for women's advancement (Bihagen \& Ohls, 2006; Dreher, 2003; Groeneveld, 2009; Kim, 2008; Zafarullah, 2000). Across cultures of the world, women are expected to be primarily responsible for child-care and household responsibilities. They often become successful in a career, while being unmarried or divorced; or, otherwise, they experience "gender penalty" in career advancement (Bihagen \& Ohls, 2006). The need to care for a child pushes women to interrupt their career (Groeneveld, 2009), makes a quick return problematic due to "unwelcoming environment" created by colleagues sharing patriarchal views (Choi \& Park, 2014, p. 129), shortens the hours a women can devote to work due to competing responsibilities (Ohemeng \& Adusah-Karikari, 2015). Household and child-care responsibilities disproportionally assigned to women influence their labor market aspirations (Bihagen \& Ohls, 2006), make them seek part-time jobs, and avoid leadership positions (Eagly \& Carli, 2007). On top of that, women in fertile ages are stereotyped as less reliable and are not assigned career advancing responsibilities (Bihagen \& Ohls, 2006). As a consequence, women get less opportunities and work experience and cannot compete for managerial positions in civil service (Caceres-Rodriguez, 2011).

\section{Leadership style constraints and male-oriented organizational culture}

A significant body of gender literature focuses on the leadership style constraints facing female leaders. Earlier literature on the topic demonstrated that women are more cooperative, relationships-oriented, emotional, and caring (Eagly \& Johanessen-Schmidt, 2001), as well as more democratic (Eagly \& Karau, 2002) leaders than their male colleagues. Women were viewed as emphasizing egalitarian and reciprocal relationships (Cammisa \& Reingold, 2004), while the male leaders were found to be more likely to display authoritarian and "top-down" style, as well as task- versus relationship-oriented type of leadership (Meier, O'Toole, \& Goerdel, 2006).

More recent literature on the topic changed the emphasis in the discussion from the difference in the extent of natural caring characteristics between males and females to the difference in societal expectations due to stereotypes. Within the literature, there is a belief that the style that is normally expected from a leader is more similar to the authoritative and transactional leadership style (Eagly \& Johenessen-Schmidt, 2001). This style is commonly associated with males due to their historical dominance, and this explains the "otherness" and undesirability of female leaders. A woman leader often finds herself in a "double bind" (Eagly \& Carli, 2007, p. 1). If a female conforms to gender stereotypes and behaves in a caring manner, she does not meet the general expectation about the appropriate leadership style. If a female is more aggressive and transactions-oriented as is normally expected from a leader, she then does not conform to the stereotypical gender-appropriate behavior. The choice of a particular leadership style depends on the actual character of a woman, as well as the organizational context (male vs. female dominated) and position in which she works.

Organizational culture in civil service is malefocused in many countries (Choi \& Park, 2014; Kim, 
2008; Maier, 1999; Vianen \& Fischer, 2002). Work in civil service is associated with long working hours, which are not acceptable for a women with children (Kim, 2008). Leaders are also expected to participate in informal meetings, such as conversations in smoking areas and after-hour happy hours (Choi \& Park, 2014; Stivers, 2002 as cited in Caceres-Rodriguez, 2011), which define membership in informal clubs essential in information sharing and in promotion decisions (Choi \& Park, 2014; Zafarullah, 2000). In many occupational fields there is a so-called good-old-boy network, created by men (Wrigley, 2002). This network suggests better opportunities for those who are the part of it (Wrigley, 2002). Much research in various fields, including civil service, found this network to be one of the barriers to women advancement to leadership positions (Stivers, 2002; Wrigley, 2002).

In addition to that, women confront negative male perceptions of women's advancement in civil service. In many countries, men see the promotion of women as a threat and do not feel comfortable to take orders from females perceiving them less capable both physically and mentally, and unsuitable for managerial positions (Bawa \& Sanyare, 2013; Connel, 2006; Holmes, 2008; Ohemeng \& Adusah-Karikari, 2015; Sabharwal, 2015). The dominant belief about lesser capacity becomes a self-fulfilling prophecy and affect ambition, self-confidence, and motivation of females (Groeneveld, 2009; McStravog, 2006).

\section{Stereotypic association of females with caring fields}

Women are often attributed such qualities as being helpful, kind, sympathetic, and sensitive. Because females are stereotypically perceived as being more caring and relationships-oriented, while males are believed to be more authoritative and task-oriented (Eagly \& Carli, 2007), as well as because females are expected to perform motherhood roles in addition to their job responsibilities, some occupations are considered to be more appropriate for characters and the lifestyle of females, while other occupations are viewed as being more appropriate for males (CaceresRodriguez, 2011). Successful female leaders in civil service often find themselves in stereotypically feminine fields, such as social protection, education, and healthcare (Dolan, 2004; Guy \& Duerst-Lahti, 1992).

\section{Strategies women use to advance}

Moving up the hierarchy ladder in civil service women develop some strategies to confront the barriers (Zafarullah, 2000). One of the key strategies is pursuing higher levels of education, which increases competitiveness with males (Ohemeng \& AdusahKarikari, 2015). Being unable to balance the household responsibilities and motherhood with civil service, women often sacrifice their family life for their career as a typical strategy (Choi \& Park, 2014). Studies indicate that there is a tendency that women in top positions in civil service are more likely to be single or divorced (Guy \& Schumacher, 2009; Tower \& Alkadry, 2008). Females also adopt prototypical characteristics of a male leader to attain higher positions in civil service (Caceres-Rodriguez, 2011; Ohemeng \& Adusah-Karikari, 2015). They act more aggressively, dress more male-like, and assume male leadership styles to be viewed favorably by the male-dominant organizations. The majority of women understand the rules made by men and they use them to their advantage. Playing by the men's rules include finding a mentor and networking (Creedon, 1991; Wrigley, 2002) or joining the "old boy clubs" by accepting informal rules that exist in the male network (Connel, 2006).

More often, women leaders rely on prototypical feminine democratic leadership styles, which allow them to gain greater power by building support from fellow women and other employees (Adusah-Karikari \& Ohenmeng, 2014, p. 577; Eagly \& Johnson, 1990). Some studies showed that women executives are more likely than their male counterparts to resolve female employees' issues, help them to balance work and family life, and tend to advance the interests of their protégés (Caceres-Rodriguez, 2011; Dolan, 2004; Adusah-Karikari \& Ohenmeng, 2014).

\section{Theories of female underrepresentation}

The existing theoretical explanations of women underrepresentation in leadership are of three types: (1) human capital theory; (2) sociopshycological theory; (3) active and passive representation theory.

Human capital approach argues that individual differences of employees, which mostly depend on personal investment decisions pertaining to education and work experience, lead to lack of women at senior management positions (Naff, 1994; Hakim, 1996, as cited in Choi \& Park, 2014). Women tend to invest less in their education and career experiences and this is the primary reason why they are less likely to advance to the highest positions (Groeneveld, 2009). However, as women started to invest more in their education and training, the human capital theory became less convincing in explaining the absence of women in high-rank positions (Choi \& Park, 2014).

Sociopsychological theory is being used to fill in the human capital theory's gap in explaining how social 
norms of the society influence individual decisions to invest in education and career (Caceres-Rodriguez, 2011). The sociopsychological theory argues that such psychological factors as women's traditional sex roles and stereotypes can pose strong barriers to women's advancement to high-rank positions by shaping social beliefs about career and leadership potential of females and self-perceptions of women about their leadership and professional abilities (Newman, 1993). Traditional sex role expectation to support their husbands and children forces women play only supporting roles rather than taking leadership and supervising roles which lead to the lack of career and leadership aspirations among women (Caceres-Rodriguez, 2011; Choi \& Park, 2014; Eagly \& Carli, 2007).

According to representative bureaucracy theory active representation of a particular group of people in bureaucracy leads to greater promotion of interests of the represented group (Sowa \& Selden, 2003 as cited in AdusahKarikari \& Ohenmeng, 2014). The active and passive representation theory argues that women working in the bureaucracy are more likely "to push for programs and issues that benefit women in the general population" (Riccucci \& Meyer, 2004, as cited in Adusah-Karikari \& Ohenmeng, 2014). More importantly, when females are not sufficiently represented, not only women's interests will not be properly observed, but also less females will aspire to pursue leadership positions.

\section{Methods}

The purpose of the study was to explore women's experiences in leadership positions in civil service in Kazakhstan. The study addressed the following research questions:

RQ1: What are the advantages and disadvantages of having females in leadership positions in civil service in view of female leaders themselves?

RQ2: What are the challenges and opportunities that females face as compared with males in performing the leadership responsibilities and advancement? Which mechanisms interfere with or facilitate female transition to and performance in the leadership positions?

RQ3: What strategies females use to advance to and succeed in leadership positions?

RQ4: To what extent type of civil service sector, age, family status, and regional residence determine differences in female leaders' experiences?
Since the purpose of our study was largely exploratory and we attempted to provide a better understanding of the experiences of female leaders in civil service in Kazakhstan, we used a simple descriptive qualitative design. We conducted 14 unstructured and 15 semistructured face-to-face and Skype interviews with females at different levels of leadership. The informal interviews were conducted at three seminars organized by the National Commission for Women and the Family, as well as gender-issues-focused local and international NGOs working in the country. The seminars involved a significant representation of females in top positions in civil service. The interviews were conducted during coffee and dinner breaks and were implemented in the form of unstructured conversations about leadership experiences of our interlocutors, whereby we did not use any predetermined set of questions and did not use a recorder or filled an interview protocol. The purpose was to identify most general themes, which were consistent or contradictory to the literature. Based on the results of the informal interviews, we developed a more structured interview protocol which was used as a data collection instrument in the formal round of interviews.

While considering the number of interviews for the formal part of the study, we relied on the recommendations of Romney, Weller, and Batchelder (1986) and Sandelowski (1995), who suggested that small sample of interviews can be quite sufficient in providing complete and accurate information within a particular cultural context, as long as the interviewees possess a certain degree of expertise about the domain of inquiry. We also took into consideration the suggestion of Guest, Bunce, and Johnson (2006), who noted that 12-15 interviews should suffice if the aim of the study is to understand "common perceptions and experiences among a group of relatively homogeneous individuals" versus to identify tendencies generalizable to the total population. While we planned to interview a larger sample of female leaders, we were constrained by the size and the poor accessibility of the population: very few women can be found in leadership positions in Kazakhstan and only a small number of them agreed to participate due to the high visibility of their positions and the resultant difficulty in achieving confidentiality. In the process of interviewing we also reached the saturation point (Glaser \& Strauss, 1967), which is an important criterion used to determine the adequacy of the qualitative sample size (Guest, Bunce, and Johnson, 2006; Onwuegbuzie \& Collins, 2007).

A maximal variation sampling was used to identify participants of the formal part of the study. Our goal was to obtain insights from females representing different 
Table 1. Profile of research participants.

\begin{tabular}{|c|c|c|c|c|c|c|c|c|c|c|}
\hline Code & Gender & Position & Sector & Region & Level & Age & $\begin{array}{c}\text { Marital } \\
\text { status }\end{array}$ & $\begin{array}{c}\text { Number of } \\
\text { children }\end{array}$ & $\begin{array}{c}\text { Experience } \\
\text { at CS }\end{array}$ & $\begin{array}{l}\text { Leadership } \\
\text { experience }\end{array}$ \\
\hline 1 & Female & Head of department & Religious affairs & North & Regional & 57 & Single & 1 & 30 & 25 \\
\hline 2 & Female & Ex-head of department & Healthcare & North & City & 45 & Single & 1 & 15 & 8 \\
\hline 3 & Female & Head of department & Social protection & North & City & 46 & Single & 0 & 11 & 1 \\
\hline 4 & Female & Head of department & Youth policy & East & Regional & 30 & Single & 0 & 9 & 8 \\
\hline 5 & Female & Head of department & Religious affairs & South & Regional & 47 & Single & 0 & 15 & 5 \\
\hline 6 & Female & Deputy Akim & City administration & North & City & 40 & Single & 0 & 15 & 8 \\
\hline 7 & Female & Deputy head of department & Education & North & City & 53 & Married & 4 & 3 & 3 \\
\hline 8 & Female & Head of department & Education & South & City & 56 & Married & 3 & 21 & 10 \\
\hline 9 & Female & Head of department & Culture & Center & City & 47 & Married & 1 & 14 & 3 \\
\hline 10 & Female & Head of department & City administration & North & City & 44 & Single & 1 & 17 & 12 \\
\hline 11 & Female & Head of department & Internal policy & East & City & 50 & Married & 2 & 7 & 7 \\
\hline 12 & Female & Head of department & City administration & North & City & 52 & Married & 2 & 20 & 20 \\
\hline 13 & Female & Head of department & Finance & North & City & 47 & Married & 3 & 10 & 10 \\
\hline 14 & Male & Deputy head of department & Internal policy & South & Regional & 40 & Married & 2 & 15 & 13 \\
\hline 15 & Female & Head of department & Internal policy & West & Regional & 45 & Married & 2 & 8 & 2 \\
\hline
\end{tabular}

backgrounds varying them in terms of: (1) their age; (2) marital and parental status; (3) sector of civil service; (4) level of governance (local, regional, national), and (5) geographic region.

Table 1 summarizes the main characteristics of the participants. A half of the participants came from the northern regions of Kazakhstan. There were slightly more representatives of the city level of governance than representatives at the regional level. Half of the participants were single. The average age of the participants was 47 years, while the average number of children was 1.5 . The participants had 14 years of experience on the average, out of which 9.5 years were in leadership positions.

The data were analyzed using interpretative coding and was framed by a combination of human capital, sociopsychological, and representative bureaucratic theories. The interpretation was somewhat guided by the thematic structure of the existing literature. However, we also left room for new interpretation given the novelty of the data arising from a study conducted in the previously unstudied context of Kazakhstan.

\section{Results}

\section{What are (dis)advantages of having female leaders in civil service?}

The participants indicated that female leaders make unique contributions to civil service. They bring a unique set of characteristics, as employees. Many participants believe that females have a high level of responsibility, persistence in carrying out a project to an end, perseverance, as well as higher expectations to quality. They are also hard-working, very detail-oriented, and comprehensive in consideration of details.

When describing the leadership style of female leaders, participants were divided in their perceptions. Many participants, especially in stereotypically female sectors, noted that a woman treats her colleagues as a family. The group of participants perceived their female bosses or themselves as more considerate of the needs of their subordinates than their male counterparts. This was particularly true in their attitudes toward female subordinates with little children: female bosses were perceived as more receptive to the fact that an employee has motherhood responsibilities and took this fact into account when assigning tasks and setting performance expectation. They allowed for more flexible work hours and would give unscheduled leaves necessary to take care of the child.

A small group of the participants (three individuals) described some negative experiences with their female bosses, whereby their supervisors were extremely aggressive and manipulative. According to the participants, such females, consistently with the available literature, perceived workplace as resource-constrained competition field, where they needed to overturn other females to succeed in the race, where males have better chances.

Some of the disadvantages of being supervised by a female leader, according to our interviewees, included a high level of expectations that they set both for themselves and others. Some female leaders feel such a high level of responsibility for the work that they work longer hours, became more controlling in monitoring of performance, and were excessively detail-oriented. This is how one of the participants described this limitation in her own words:

I have a strong sense of responsibility... If I start to do something, I have to know everything inwards and outwards and I have to achieve the topmost quality. I expect the same from my subordinates. Sometimes I have to complete the task instead of the subordinate because I want everything to be perfect.

\section{What are the challenges and opportunities that females face?}

The analysis of interviews with female leaders revealed that there seems to be an agreement that females are 
underrepresented in civil service leadership. In view of participants, this underrepresentation is not the result of discriminatory hiring or promotion practices. Many women leaders are convinced that a woman can achieve any level of leadership she wants if she is determined to do so because the gender policy of Kazakhstan has created career development and promotion opportunities for women.

At the same time, the majority of participants agree that females are less likely to advance as high as their male counterparts. The key reason behind this is societal expectations about gender roles. Women in Kazakhstan are traditionally perceived "a weak gender" with physical abilities inferior to those of males. The genetically determined difference justifies in the view of the society the gender-based division of labor and the traditional family structure where a male plays the role of the breadwinner and the female plays the role of the caretaker. Hence, the cultural expectation is that the primary role of a woman is within a family. This is what one of the participants said in this regard:

We have very Asian mentality. When you come home, you are expected to devote yourself completely to domestic chores. When I come home I have to cook the evening meal because my husband when strangers cook for him does not like to eat out...The challenge is that my husband comes home, watches TV, relaxes after work, while I have to do everything around the house....

Unlike some more orthodox societies, in Kazakhstan the professional and the family role of a woman are not mutually exclusive; rather priority is assigned to family responsibilities. Both males and females believe that females are free to pursue a career as long as they can make an arrangement whereby caretaking role is performed by either another extended family members or caretaking facilities. Moreover, as neoliberal reforms and accompanying Western values proliferated in Kazakhstan the view of a female as an economically important member of the workforce and as an essential contributor to family's earnings seem to have strengthened. Many participants noted that younger females have more career and leadership ambitions, while younger males are increasingly receptive of the idea that a female can be the primary breadwinner in the family.

In the complicated context where traditional society values are intertwined with the novel expectations for female participation in the labor force, several sources of female underrepresentation in leadership roles were noted by participants. First, females do not have aspiration to leadership. None of the participants of the interviews were strategic about building a career as a leader. They all claimed that they ended up in leadership positions without any efforts or plans to receive a leadership role, and moreover, frequently against their will. As one of the participants mentioned:

When I analyze my life I recall that I never had a desire to make a career, to try to advance. When I was promoted, it just happened to me. ...When I was offered a leadership position, my sense of responsibility did not allow me to decline the offer. I did not even ask about salary increases. If you are offered a position, you are being trusted and it is not polite to say "no."

The second source of the underrepresentation of females is the difficulty in combining leadership and family responsibilities during early stages of career, which overlap with the most demanding years of motherhood. At the early stages, when a woman has to establish her reputation as a leader and gain experience, she also has to perform responsibilities of a mother. Work hours in civil service in general are very long and inflexible. Meanwhile, the societal view that only mother can take care of a young child is so strong that males do not consider replacing their successful wives in the caring role and employers ask interview questions about the kind of arrangements for child-care she is planning. Employers also do not differentiate among male and female employees in terms of work load expectations and ignore the fact that a woman has to balance her family and professional roles. Several participants claimed: "At work I am a civil servant, I am not a woman." Given the challenge of combining the family and professional roles, participants noted that many female leaders in civil service are more likely to advance before they are married, after their kids grow up, or if they are not married and have no kids.

As a result of the unresolvable conflict between parental and leadership roles, females avoid leadership responsibilities at the early child-rearing age and fail to gain experience that would allow to advance them as far as males later in life. This explains a small number of females at top leadership positions, as well as in positions in such sectors as industry or economic policy, which require comprehensive understanding of processes formed by going through the whole career vertical. The largely shared belief here is that females tend to be good at details, but fail to develop a bird-view of a process. One of the reasons for females' inability to think strategically is upbringing of girls, which prepares them for secondary family role, where she is subordinate and should follow orders rather than strategize.

Another barrier to women advancement to leadership is the nature of civil service career. Not only civil 
service employees have to work long hours, but there is an assumption among them that work is priority and one has to make arrangements for other aspects of their life. Second, many participants pointed to the fact that corruption is still present in civil service and that it might be linked to leadership responsibilities. Because of child-caring responsibilities, females are more risk averse and avoid positions, which may lead to a risk of being accused of corruption. Finally, many participants observed that protectionism is still widespread and presents the main challenge to advancement not only for talented females but also for males.

If our government paid a greater attention to smart people, we might have had more females than males. Although relatives and acquaintances are not allowed to be hired as coworkers, we still have it in our system.

I think females are afraid of taking bribes. I always tell my employees: you'd better go hungry than lose sleep (due to bribing).

An additional barrier to female advancement to leadership positions is the male-favoring view of an ideal leader in the society. For certain areas, such as internal affairs, religious affairs, or military advancement of females to high-level leadership positions is highly unlikely because the majority of the employees in the sectors are males.

I experience difficulties in dealing with certain categories of population-male population to be more accurate...with old males in particular (aksakals)... Local citizens refer to me as a "kelin" (daughter in law) or as "kyz" (a young girl)...I had to fight for my niche and earn respect from the population.

The participants of the interviews were also asked about the mechanisms and strategies that facilitate their transition to and performance of leadership responsibilities. Three mechanisms were particularly notable here. First, many noted the importance of a mentoring female, who occupied a superior position in the organization. Second, successful females frequently received substantial support from their families. They had understanding husbands or relatives, who assumed some housekeeping and child-care responsibilities. Finally, successful leaders are highly efficient in managing their time. They frequently strictly distinguish between their time at work and time at home. Some are saying that they keep their two conflicting identities-that of a mother and that of a leader, separately from each other. This is how one participant described this approach:

I never mix my work and my home. When I come back I stop being a leader. I can come at 10 at night on the weekdays, but on the weekend I am making dumplings in batches. I try to sleep well and I plan everything ahead.... I cannot afford leaving anything for tomorrow because the work will accumulate.

\section{What strategies females use to advance to and succeed in leadership positions?}

Many of our participants mentioned that they never wanted to become leaders and that they were promoted based on their performance frequently against their own will. However, we were able to determine two key approaches that females used to deal with the responsibilities of a leader. These two approaches can be described as reliance on either female or male leadership styles.

Some of the females assumed a stereotypically "female" type of leadership, whereby they treated their supervisees as a family. When describing this style of leadership, the participants frequently used motherhood and sisterhood as metaphors to describe their relations with colleagues. Some believed that making sure that everyone felt at home at their workplace is one of their responsibilities as a leader. Others mentioned that their advancement and success as a leader is largely dependent on the support of their sister-colleagues, whom they referred to for advice. Still others strongly believed in creating career development opportunities for their subordinates, mentoring them in the process of growth, and encouraging them to seek leadership responsibilities. This type of leadership was often used by females at the beginning of their leadership careers, when the level of responsibility and the competition from males was not too high. Also, it was more frequently used by women working in traditionally female sectors. In words of a participant of the study:

I have this caring attitude to my younger female colleagues. Before I started in leadership role, I have read a lot about leadership styles. The salary in the civil service is very low. We have to work after work hours and come to work on weekends and holidays. That is why healthy human relations in the team are very important.

Another style of leadership was more transactionoriented. Women with this leadership style showed much less concern for their supervisees, tended to select, promote, and develop employees based on the needs of the organization and performance of the subordinate. They did not connect to their subordinates on the personal level and often allied more with male colleagues. Such women tried to seem rational, putting the professional persona ahead of their identity as a woman. They tried hard to be acknowledged by male colleagues, penetrate their informal clubs, and become recognized for 
their professionalism. This kind of style was more frequently used by females, who were struggling to receive recognition due to their young age and single status. It was also very typical for females at higher levels of authority, seemingly due to increasing competition from males and higher level of responsibility.

\section{To what extent type of civil service sector, age, family status, and regional residence determine differences in female leaders' experiences?}

One of the questions pursued in the interviews was aimed at revealing any differentiation among females in terms of leadership experiences. We were particularly interested in comparing the experiences of females with different family status, residing in different regions of Kazakhstan, working in male- and female-dominated sectors, and representing different generations. Below is a summary of the main findings.

First, we found that females' advancement opportunities are directly related to their family status, since motherhood responsibilities seem to be the main interference in the career growth of a woman. The dependence of female performance on the stage in motherhood is well recognized by the employers, and women are offered better promotion opportunities and are advanced either earlier in their life or after their children have become independent. Some employers may discriminate against younger single females:

When a new specialist is being interviewed we always ask whether they are married or not and whether they have children. I always think who will be replacing the woman if she takes a pregnancy leave.

Second, many participants indicated that female leadership advancement opportunities vary by region. The capital city of Astana seems to have favorable opportunities for female advancement. One participant provided an interesting explanation of the fact: civil service agencies in Astana often serve as testing grounds for reforms and practices. Hence, the quality of implementation is highly important and leaders should have a high sense of responsibility, commitment to quality and detail orientation. These characteristics, as has been stated above, are more common in female leaders. In addition to that, many participants noted that the more tradition-oriented regions of southern Kazakhstan offer less career advancement opportunities for females. Females in these regions grew up in conservative families and have less career aspirations, they also experience stronger pressure to stay at home. In addition to that, male-favoring leader stereotypes and the level of corruption and protectionism tend to be stronger there.

Interestingly, Mangystau, which is generally considered a conservative region have a high female representation in leadership. One of the explanations provided by a participant was that males in the region are less interested in the career in civil service in general due to the availability of better paid jobs in the oil sector. Below is a quote from a participant describing regional differentiation:

In our Pavlodar region people are judged only by their professional characteristics. They are entrusted a particular leadership role because they are viewed as being experienced and capable, because they would be preoccupied with their job rather than with advancement of their relatives. These kinds of cases happen in the south.

Third, we definitely identified some differences in female experiences in female- and male-dominated sectors. Female-dominated sectors offer better opportunities for growth and more favorable job contexts. Since the majority of employees in the female-dominated spheres are women, there is less competition and conflict in the workplace. In addition to that, the nature of work in the sectors is better aligned with the traditional expectations about gender roles and with stereotypical view of a female as highly emotional and caring. Finally, these spheres have well-developed culture and procedures for mentoring and promotion from within and out of females. In male-dominated areas, the advancement is less likely and the work environment is much less favoring of a woman, who is forced to compete with males, has to assume a male leadership style, and has to hide her family-related identity. Interestingly, female leaders in the context tend to choose males as role.

Finally, many participants mentioned generational difference in the career development approaches among females. While most of the participants themselves mentioned that they were not planning to become leaders, they noted that their younger counterparts are much more career-oriented and ambitious, and are not shy to assume leadership responsibilities. They also tend to postpone starting a family as a result of their preoccupation with career advancement.

We used to have this old mentality, where the status of a male was always higher than that of a female. Nowadays, using an example of a colleague, who is 10 years younger, I know that she gets all the support from her husband. This makes me think that our mentality is changing.

\section{Conclusion}

The study revealed some very important findings about the experiences of female leaders in Kazakhstan. 
The main finding is that in Kazakhstan there is no formal discrimination of females in promotion to leadership positions. However, there are some barriers, which are predicted by the combination of human capital, sociocultural, and active and passive representation theories.

Human capital theory predicts that females will have less opportunities for advancement compared with males due to the lower level of education. While females leaders in Kazakhstan are educated as well as their male counterparts, their education is not necessarily the type, which is valued in leaders. Girls are trained in Kazakhstan to be detail-oriented, neat, and responsible, while a leader is expected to have the ability to see the big picture and to strategize. From this point of view, females might be viewed by employers as having less relevant human capital and are not chosen for promotion.

Another prediction of the human capital theory would be that females would invest their human capital in a leadership career when this career brings proper returns. However, women have to distribute their human capital between their family and work responsibilities. The return on investment in raising children is culturally perceived as higher. This explains lack of aspirations in females and the sacrifice of the family life that some of them are making when choosing to invest in leadership career.

The relevance of sociopsychological theory is most evident in our findings. The primary barriers to female advancement in leadership positions in civil service in Kazakhstan are linked to the dominant societal expectations that (1) a woman's primary role is in the family, where she plays the role of a servant of her husband and children, and she should be emotional and caring, while a male is the breadwinner and should be rational and uninvolved; (2) a good leader should have a rational, masculine style of leadership, and hence the role is more appropriate for a male; (3) a civil service employee is a servant of the state, who should sacrifice their personal life for the interests of the job. A woman, who chooses to pursue a leadership role in civil service faces conflicting cultural expectations about her performance as a mother and her performance as a civil service leader.

Finally, one of the predictions of the representative bureaucracy theory would be that more women would have aspirations for leadership and would have better chances to get promoted if they are actively represented in civil service leadership. Many of our participants noted the importance of having role models, of being mentored and supported by other females. In addition to that, low representation of females in civil service leadership posts might explain the observed lack of aspirations for leadership among younger and older females.

The majority of the findings of the article are very consistent with prior research conducted using the data from other countries. The barriers that females face and the strategies that they use are typical for women in similar positions from other countries. Women in Kazakhstan have to juggle their responsibilities of a mother/wife and a leader while being underappreciated, undersupported, and overburdened. What is unique in Kazakhstan is that a woman faces two sets of competing cultural expectations-one associated with the traditional view of gender-based division of labor; and the other associated with the neoliberal view based on economic rationale for female employment outside the family. The exact configuration of pressures from the two sets of expectations varies depending on the geographic location, age, and the stage of leadership development of a woman.

Taking into consideration the finding that females bring a unique set of valuable characteristics to organization as leaders, it is important to achieve a greater representation of females in civil service leadership.

The following actions are recommended based on the results of our study:

(1) Introduction of a legal requirement to have a balanced representation of females and males in decision-making positions in the government.

(2) Offering gender training courses for government officials and the political elite to improve their awareness of gender stereotypes and gendered practices at work.

(3) Provision of training for women who demonstrate leadership capacity in civil service.

(4) Development of career development plans taking into consideration the child-care responsibilities.

(5) Improvement of work conditions to allow females to balance their work and family responsibilities:

(a) provision for flexible working hours and distance-work for females with young kids;

(b) strict adherence to 8-hour work day and 5-day work week;

(c) mentorship by other female leaders;

(d) encouragement provided for males to take paternity leaves. 


\section{Acknowledgements}

The authors would like to thank the Norwegian Institute of International Affairs (NUPI) for their funding of this research within South Caucasus and Central Asia program "Research Beyond the Ivory Tower".

\section{References}

Adusah-Karikari, A., \& Ohemeng, F.L.K. (2014). Representative bureaucracy in the public service? A critical analysis of the challenges confronting women in the civil service of Ghana. International Journal of Public Administration, 37(9),568-580.

Bawa, S., \& Sanyare, F. (2013). Women's Participation and Representation in Politics: Perspectives from Ghana, International Journal of Public Administration, 36:4, 282291.

Bihagen, E., \& Ohls, M. (2006). The glass ceiling-where is it? Women's and men's career prospects in the private vs the public sector in Sweden 1979-2000. The Sociological Review, 54(1), 20-47. doi:10.1111/j.1467954X.2006.00600.x

Bowling, C. J., Kelleher, C. A., Jones, J., \& Wright, D. S. (2006). Cracked ceilings, firmer floors, and weakening walls: Trends and patterns in gender representation among executives leading American state agencies, 1970-2000. Public Administration Review, 66(6), 823-836. doi:10.1111/j.1540-6210.2006.00651.x

Brudney, J. L., Hebert, F. T., \& Wright, D. S. (2000). From organizational values to organizational roles: Examining representative bureaucracy in state administration. Journal of Public Administration Research and Theory, 10 (3), 491-512. doi:10.1093/oxfordjournals.jpart.a024278

Caceres-Rodriguez, R. (2011). The glass ceiling revisited: Moving beyond discrimination in the study of gender in public organizations. Administration \& Society, 20(10), 1-36.

Cammisa, A. M., \& Reingold, B. (2004). Women in state legislatures and state legislative research: Beyond sameness and difference. State Politics \& Policy Quarterly, 4(2), 181210. doi:10.1177/153244000400400204

Choi, S., \& Park, C.-O. (2014). Glass ceiling in Korean civil service analyzing barriers to women's career advancement in the Korean government. Public Personnel Management, 43(1), 118-139. doi:10.1177/0091026013516933

Connel, R. (2006). The experience of gender change in public sector organizations. Gender, Work \& Organization, 13(5), 435-452. doi:10.1111/gwao.2006.13.issue-5

Creedon, P. J. (1991). Public relations and" women's work": Toward a feminist analysis of public relations roles. Journal of Public Relations Research, 3(1-4), 67-84. doi:10.1207/s1532754xjprr0301-4_3

Dahlerup, D. (1978). Women's entry into politics. The experience of the Danish local and general elections 1908-20. Scandinavian Political Studies, 1(2-3), 139-162. doi:10.1111/j.1467-9477.1978.tb00174.x

Dolan, J. (2004). Gender equity: Illusion or reality for women in the federal executive service? Public Administration Review, 64(3), 299-308. doi:10.1111/puar.2004.64.issue-3

Dreher, G. F. (2003). Breaking the glass ceiling: The effects of sex ratios and work-life programs on female leadership at the top. Human Relations, 56(5), 541-562. doi:10.1177/ 0018726703056005002

Eagly, A. H., \& Carli, L. L. (2007). Through the labyrinth: The truth about how women become leaders. Harvard Business School Press.

Eagly, A.H., \& Johannesen-Schmidt, M.C. (2001). 'The leadership styles of women and men. Journal of Social Issues. 57(4),781-797.

Eagly, A. H., \& Johnson, B. T. (1990). Gender and leadership style: A meta-analysis. Psychological Bulletin, 108, 233-256. doi:10.1037/0033-2909.108.2.233

Eagly, A. H., \& Karau, S. J. (2002). Role congruity theory of prejudice toward female leaders. Psychological Review, 109 (3), 573-598. doi:10.1037/0033-295X.109.3.573

Glaser, B. G., \& Strauss, A. L. (1967). The discovery of grounded theory: Strategies for qualitative research. Chicago: Aldine Pub. Co.

Groeneveld, S. (2009). Careers in the Dutch civil service: A gender perspective. International Review of Administrative Sciences, 75(3), 493-507. doi:10.1177/0020852309337685

Guest, G., Bunce, A., \& Johnson, L. (2006). How many interviews are enough? An experiment with data saturation and variability. Field Methods, 18(1), 59-82.

Guy, M. E., \& Duerst-Lahti, G. (1992). Agency culture and its effect on managers. In M. E. Guy (Eds.), Women and men of the states: Public administrators at the state level. Armonk, NY: M.E.Sharpe, pp.157-188.

Guy, M.E., \& Newman, M.A. (2004). Women's Jobs, Men's Jobs: Sex Segregation and Emotional Labor. Public Administration Review, 64(3),289-298.

Guy, M. E., \& Schumacher, K. L. (2009). A retrospective analysis of scholarship on gender and diversity in public administration. Paper presented at the Annual Meeting of the American Political Science Association, Toronto, Canada, September 3-6..

Hakim, C. (1996). Key issues in women's work: Female heterogeneity and the polarisation of women's employment. Atlantic Highlands, NJ: Athlone Press.

Holmes, J. (2008). Gendered talk at work: Constructing gender identity through workplace discourse (Vol. 3). Chichester, UK: John Wiley \& Sons LTD.

Inter-Parliamentary Union. (2014). Women in national parliaments. Retrieved from http://www.ipu.org/wmn-e/arc/ classif010514.htm

Katz, K. (2001). Gender, Work and Wages in the Soviet Union: A legacy of Discrimination. New York: Palgrave.

Kandiyoti, D. (2007). Old Dilemmas or New Challenges? The Politics of Gender and Reconstruction in Afghanistan. Development and Change, 38(2),169-199.

Kim, C.-K. (2004). Women in the Korean civil service. International Journal of Public Administration, 26(1), 6178. doi:10.1081/PAD-120018295

Kim, S. (2008). Women and family-friendly policies in the Korean government. International Review of Administrative Sciences, 74(3), 463-476. doi:10.1177/0020852308095313

Maier, M. (1999). On the gendered substructure of organization: Dimensions and dilemmas of corporate masculinity. In G.N.Powell (Ed.), Handbook of gender and work (pp. 69-94). Thousand Oaks, CA: Sage.

McBride, D. E., \& Parry, J. A. (2016). Women's rights in the USA: Policy debates and gender roles. 4th Edition, New York: Routledge. 
McStravog, D. (2006). Barriers to Female Progression to Senior Positions within the 26 District Councils in Northern Ireland. Local Government Staff Commission and the Local Government Training Group. Retrieved from:www.womeninlocalcoincils.org.uk

Meier, K. J., O’Toole, L. J., \& Goerdel, H. T. (2006). Management activity and program performance: Gender as management capital. Public Administration Review, 66 (1), 24-36. doi:10.1111/puar.2006.66.issue-1

Naff, K. C. (1994). Through the glass ceiling: Prospects for the advancement of women in the federal civil service. Public Administration Review, 54, 507-514. doi:10.2307/976669

Naff, K. C. (2001). To look like America: Dismantling barriers for women and minorities in government. Boulder, CO: Westview Press.

Newman, M. A. (1993). Career advancement: Does gender make a difference? The American Review of Public Administration, 23(4), 361-384. doi:10.1177/027507409302300404

Nurlybek. (2015). How many women in the Kazakh government and politics. Women and Expo. http://expoandwomen.com/ en/how-many-women-in-the-kazakh-government-andpolitics/

Ohemeng, F. L. K., \& Adusah-Karikari, A. (2014). Breaking through the glass ceiling: Strategies to enhance the advancement of women in Ghana's Public Service. Journal of Asian and African Studies, 0021909614530381.

Ohemeng, F. L. K., \& Adusah-Karikari, A. (2015). Breaking through the glass ceiling: Strategies to enhance the advancement of women in Ghana's Public Service. Journal of Asian and African Studies, 50(3),359-379.

Onwuegbuzie, A. J., \& Collins, K. M. T. (2007). A typology of mixed methods sampling designs in social science research. The Qualitative Report, 12(2), 281-316.

Pascall, G., \& Manning, N., (2000), Gender and social policy: comparing welfare states in Central and Eastern Europe and the former Soviet Union, Journal of European Social Policy, 10(3), 269-96.

Riccucci, N.M. and Meyers, M.K. (2004) Linking Passive and Active Representation: The Case of Frontline Workers in Welfare Agencies. Journal of Public Administration Research and Theory, 14 (4), pp. 585-97.

Romney, A. K., Weller, S. C., \& Batchelder, W. H. (1986). Culture as consensus: A theory of culture and informant accuracy. American Anthropologist, 88(2), 313-338. doi:10.1525/aa.1986.88.issue-2
Rudman, L. A., Moss-Racusin, C. A., Phelan, J. E., \& Nauts, S. (2012). Status incongruity and backlash effects: Defending the gender hierarchy motivates prejudice against female leaders. Journal of Experimental Social Psychology, 48(1), 165-179. doi:10.1016/j.jesp.2011.10.008

Ryan, M. K., \& Haslam, S. A. (2005). The glass cliff: Evidence that women are over-represented in precarious leadership positions. British Journal of Management, 16(2), 81-90. doi:10.1111/bjom.2005.16.issue-2

Sabharwal, M. (2015). From glass ceiling to glass cliff: Women in senior executive service. Journal of Public Administration Research and Theory, 25(2), 399-426. doi:10.1093/jopart/mut030

Sandelowski, M. (1995). Focus on qualitative methods. Sample size in qualitative research. Research in Nursing and Health. 18(2),179-183.

Sowa, J. E., \& Selden, S. C. (2003). Administrative Discretion and Active Representation. An Expansion of the Theory of Representative Bureaucracy. Public Administration Review, 63(6), 700-710.

Stivers, C. (2002). Gender images in public administration: Legitimacy and the administrative state. (2nd ed). Thousand Oaks, CA: Sage Publications.

Tower, L. E., \& Alkadry, M. G. (2008). The social costs of career success for women. Review of Public Personnel Administration, 28, 144-165. doi:10.1177/0734371X08315343

Vianen, A. E. M., \& Fischer, A. H. (2002). Illuminating the glass ceiling: The role of organizational culture preferences. Journal of Occupational and Organizational Psychology, 75(3), 315-337. doi:10.1348/0963179023 20369730

Wrigley, B. J. (2002). Glass ceiling? What glass ceiling? A qualitative study of how women view the glass ceiling in public relations and communications management. Journal of Public Relations Research, 14(1), 27-55. doi:10.1207/S1532754XJPRR1401_2

Yap, M., \& Konrad, A. M. (2009). Diferenciales de género y de raza en las promociones: ¿existe un piso pegajoso, un cuello de botella de nivel medio o un techo de vidrio? Relations Industrielles/Industrial Relations, 64, 593-619. doi:10.7202/038875ar

Zafarullah, H. (2000). Through the brick wall, and the glass ceiling: Women in the civil service in Bangladesh. Gender, Work \& Organization, 7(3), 197-209. doi:10.1111/ gwao.2000.7.issue-3 